Wilfrid Laurier University

Scholars Commons @ Laurier

Spring 2002

\title{
Sharing Power and Knowledge: Professional and Mental Health \\ Consumer/Survivor Researchers Working Together in a \\ Participatory Action Research Project
}

\author{
Joanna Ochocka \\ Centre for Research and Education in Human Services \\ Rich Janzen \\ Centre for Research and Education in Human Services \\ Geoffrey Nelson \\ Wilfrid Laurier University, gnelson@wlu.ca
}

Follow this and additional works at: https://scholars.wlu.ca/psyc_faculty

Part of the Psychiatry and Psychology Commons

\section{Recommended Citation}

Ochocka, Joanna; Janzen, Rich; and Nelson, Geoffrey, "Sharing Power and Knowledge: Professional and Mental Health Consumer/Survivor Researchers Working Together in a Participatory Action Research Project" (2002). Psychology Faculty Publications. 12.

https://scholars.wlu.ca/psyc_faculty/12

This Article is brought to you for free and open access by the Psychology at Scholars Commons @ Laurier. It has been accepted for inclusion in Psychology Faculty Publications by an authorized administrator of Scholars Commons@ @aurier. For more information, please contact scholarscommons@wlu.ca. 


\section{Sharing Power and Knowledge: Professional and Mental. Health Consumer/Survivor REsearchers Working Together in a Participatory Action Research Project}

\author{
JOANNA OCHOCKA, \\ RICH JANZEN \& \\ Geoffrey Nelson
}

JOANNA OCHOCKA, PHD. IS THE CENTRE COORDINATOR AT THE CENTRE FOR RESEARCH AND EDUCATION IN HUMAN SERVICES. KITCHENER, ONTARIO, CANADA.

RICH JANZEN. MA. IS A SENIOR RESEARCHER AT THE CENTRE FOR RESEARCH AND EDUCATION IN HUMAN SERVICES.

GEOFFREY NELSON, PHD. IS A PROFESSOR IN THE DEPARTMENT OF PSYCHOLOGY. WILFRID LAURIER UNIVERSITY, WATERLOO. ONTARIO, CANADA.

FOR INFORMATION CONTACT THE PRIMARY AUTHOR AT THE CENTRE FOR RESEARCH AND EDUCATION IN HUMAN SERVICES, 73 KING ST. W. SUITE 202, KITCHENER, ON, CANADA N2G 1A7. TEL: $519 / 741-1318$.

E-MAIL:joanna@crebs.on.ca

In this article we document and reflect on the process and outcomes of consumer/survivor researchers' involvement in a community mental bealth research project. The study used a participatory action research approach that challenges traditional assumptions of bow to conduct research. Research roles and relationships were reexamined by both professional and consumer/survivor researchers. Four values were central to the research process: consumer/survivor empowerment, supportive relationships, learning as an ongoing process, and social justice. The benefits of this value-driven approach were seen in terms of positive impacts on the lives of individual researchers and also in the quality of the research itself. Our reflections on the research process have led us to see the importance of building relationships as a means to share power and knowledge among professional and consumer/survivor researchers.

\section{${ }^{6} T_{\text {he right to evaluate mental }}$ health services by a consumer/ survivor could be similar to a civil jury's findings based on witness testimony. Psychiatric consumer/ survivors are both witnesses to the system and the reason for the sys- tem existence. The system serves them." \\ -Consumer/survivor researcher \\ Consumer/Survivor Participation and Involvement in Mental Health Systems}

In recent years the community mental health system in some communities has undergone a major paradigm shift in terms of our understanding of who has both the right and the experience and knowledge to participate in decision- making processes (Carling, 1995;

Nelson, Lord, \& Ochocka, 2001;

Trainor, Pomeroy, \& Pape, 1999). There is an increasing recognition that people with mental health problems can and should actively contribute to planning and evaluating support services intended to be helpful to them. Calls for such participation are grounded in the belief that people with mental health problems, many of whom call themselves "consumer/survivors," are a disadvantaged group, and that participation is one vehicle for consumer/survivor empowerment (Lord \& Dufort, 1996). Consumer/survivors often experience a lack of power and control, are stigmatized and excluded from community 
life, and live in conditions of poverty, unemployment, and poor housing (Nelson et al., 2001).

Also, there is a continued imbalance of power between consumer/survivors and mental health professionals (Constantino \& Nelson, 1995; Lord \& Dufort, 1996; Mason \& Boutilier, 1996; Nelson et al., 2001; Vandergang, 1996). Professionals are accorded considerable power by virtue of their education and training, and this power is typically unstated and hidden within professional organizations and relationships with consumer/survivors. The invisibility of power relations poses further challenges to overcoming power imbalances. Power is also manifested at the individual level through individual perceptions of their own power and that of others (Constantino \& Nelson, 1995; Mason \& Boutilier, 1996; Prilleltensky \& Gonick, 1996).

The literature on consumer/survivor participation and involvement is limited and has focused primarily on two areas: (a) the potential benefits resulting from consumer/survivor participation in decision-making (Church, 1996; Trainor et al., 1999; Vandergang, 1996; Wilson, 1996), and (b) the barriers to and supports for successful partnership efforts between service organizations and consumer/survivors (Carling, 1995; Church, 1992; Lord \& Church, 1998; MacGillivary \& Nelson, 1998; MorrellBellai \& Boydell, 1994; Nelson et al., 2001; Ochocka, Nelson, \& Lord, 1999; Wilson, 1996).

To move toward more desired relationships between mental health professionals and consumer/survivors, several strategies for change have been suggested in the literature. First, changes in professional ideology and practice can be facilitated by educating professionals about shifts in their roles and ongoing interactions with consumer/survivors in order to build understanding and trust
(Constantino \& Nelson, 1995; Ochocka et al., 1999; Stewart, Banks, Crossman, \& Poel, 1994). Second, increased participation and involvement in decisionmaking in mental health policy, planning, service delivery, and research by consumer/survivors has been suggested to reduce power imbalances (Church, 1992; Trainor et al., 1999). Power and control (of knowledge and resources) are critical dimensions of the relationship between professionals and consumer/survivors (Lord \& Dufort, 1996)

\section{Consumer/Survivors as Researchers}

Given the emerging emphasis on consumer/survivor participation and involvement in service delivery, it is not surprising that consumer/survivors have slowly become more involved in research dealing with mental health issues. They may be involved as active participants (Morrell-Bellai \& Boydell, 1994), they may direct the research process (Vuong \& St-Amand, 1993), or they may participate in developing directions for future research (Canadian Alliance for Research on Schizophrenia, 1994). For example, in the 1990s consumer/survivor researchers became somewhat more common in mental health studies as partners to professional researchers (e.g., Mason \& Boutilier, 1996; Morrell-Bellai \& Boydell, 1994; Srebnick, Robinson, \& Tanzman, 1990; Woodside, Cikalo, \& Pawlick, 1995). This type of involvement in research raises issues related to the power imbalance between professional researchers and consumer/survivor researchers.

Understanding the implications of having consumer/survivors fully involved in a research process is still very limited. While we know that the strengths of each member of the research team, including consumer/survivor researchers, are invaluable, and that a good working relationship among professionals and consumer/survivors in research repre- sents an "exciting possibility" (Woodside et al., 1995), there is still much to be learned. Particularly, there is a limited understanding regarding strategies to encourage inclusiveness and to create "normal work" environments with meaningful participation, shared power and knowledge, and authentic relationships among all involved.

In this article, we present value-driven strategies that were successful in reducing power differences between professional and consumer/survivor researchers in a research study. We begin by describing how our research team was formed and then describe and discuss how four values guided the work of the research team. We end by highlighting the importance of building relationships within the research team.

For the purposes of our study we defined consumer/survivor researchers as people with little or no formal training and experience in doing research, people with the stigma of being "unemployable," and people who have experienced mental health problems. Our research was an example of collaboration among professional researchers, who have skills and knowledge in research, and consumer/survivor researchers who have knowledge of and experience in the mental health system. It is also an example of a study that consciously sought to reduce traditional power imbalances between consumer/ survivor and professional researchers.

While professional researchers authored this paper, we have included the quotations from consumer/survivor researchers throughout. Elsewhere the consumer/survivor researchers themselves have written about their experiences within this research project (Reeve, Cornell, \& D'Costa, 1998).

\section{Background to the Research Study}

This article is based on a two and a half year research project coordinated by the 
Center for Research and Education in Human Services', entitled "Shifting the Paradigm in Community Mental Health: A Community Study of Implementation and Change." The study was undertaken in Kitchener-Waterloo, a community of 300,000 people, located in Southwestern Ontario, Canada. The study was a collaborative effort between research partners (Wilfrid Laurier University and the Center for Research and Education in Human Services) and three community mental health organizations (the Canadian Mental Health Association/ Waterloo Regional Branch, Waterloo Regional Homes for Mental Health and Waterloo Region Self Help). A team of professional researchers and consumer/ survivor researchers was formed. This team carried out all research activities related to the project. Training and ongoing support to consumer/survivor researchers became integral parts of the research process.

The overarching goal of the research was to understand the experience of change as three mental health organizations strove to implement an empowerment-community integration paradigm (Nelson et al., 2001). Traditionally, community mental health has its roots in psychiatry and the medical model. Similarly, social science has been dominated by "positivism" as the worldview for 3 centuries. We realized that studying the "emerging paradigm" in community mental health required an innovative research approach. The study used a participatory action research approach (Nelson, Ochocka, Griffin, \& Lord, 1998) and the assumptions of a social-constructivist paradigm (Lincoln \& Guba, 1985).

In our project, traditional research roles were challenged. Consumer/survivor researchers became new scientists access- ing and contributing information and knowledge. The role of professional researchers changed from expert to facilitator, trainer, and supporter. During our research study, we were not only learning about the organizations and change in community mental health, but we were also constantly learning about new ways to conduct participatory action research. For example, at the beginning of the project we had not expected that consumer/survivors would be participating in every aspect of the research, including writing up the findings and presenting them. Researcher roles changed as the research evolved.

\section{Case Study-Implementing Values and Principles}

The research team consisted of two professional researchers at the Center for Research and Education, two university graduate students in community psychology, and three consumer/survivor researchers who had at some time received support from one of the three community mental health organizations involved in the study. All members of the research team were paid for their work on this project. The two primary investigators ${ }^{2}$ of the project had a standing invitation to attend the research team meetings and did so occasionally.

We not only wanted to have a rigorous methodology, but we also wanted to have a successful process working as a team of researchers. When we started to plan how and with whom we would work on this study, we engaged ourselves in discussions of working principles. We intentionally followed a set of values, which we have described in another paper (Nelson, et al., 1998), to guide the work of this research project with consumer/survivors. We believed that these values could be practically applied to our research study and would reduce power imbalances between professional and nonprofessional researchers. Empowerment, social support, "learning as we go," and social justice were the main guiding principles around which we organized work with our research team. For each of these values, we discuss strategies and findings and then reflect on these findings in terms of existing theory and research.

Empowerment. Empowerment is a value that is characterized by choice and participation (Rappaport, 1987) and by the enhancement of psychological and political power (Park, 1993). To increase power and participation in our study we facilitated processes that gave voice and choice to the individual researchers and to the whole research team. We strived to use plain language rather than professional jargon, to encourage and listen to researchers' contributions and to negotiate difficult issues openly. All these strategies helped to reduce the gap between professionals and consumer/ survivors.

It was very empowering to be asked about my opinions and positions. The leaders shared the power through seeking consensus and including all team members in decision making. (consumer/survivor researcher)

Control and ownership over the research process and research findings were shared among all research team members. This was important in order to create an atmosphere of inclusion and to share responsibilities of the research. For example, we all participated in tasks and decisions related to data gathering (e.g., professional and nonprofessional researchers were paired to facilitate focus groups) to data analysis and feedback (e.g., all researchers presented findings within each of the three

\footnotetext{
Center for Research and Education in Human Services is a nonprofit organization that conducts participatory action research locally, provincially and nationally. 'Geoff Nelson, Department of Psychology, Wilfrid Laurier University and John Lord, Social Research Consultant.
} 
community organizations and at a community forum).

In terms of choice over disclosure, consumer/survivor researchers were not asked or expected to declare to participants the fact that they received support from mental health services. In some cases, the participants of the research knew that the researchers were mental health consumers; in other cases they did not. In fact, each of the three researchers hired held different views on whether they wanted to publicly disclose their mental health issues. One researcher was very open and vocal about being a consumer/survivor. Another was selective to whom and when $\mathrm{s} / \mathrm{he}$ would disclose her/his mental health issues. The third felt uncomfortable identifying with the consumer/survivor movement and was still coming to terms with her/his mental health struggles.

Our desire to work with our collaborators as equals facilitated the empowerment process. We were determined to enable consumer/survivor researchers to build upon their capacities in order to contribute to their future lives (e.g., employment possibilities, better quality of life):

\begin{abstract}
A benefit was being able to have a voice at our team meetings, to influence decisions. I felt I was empowered to play an important role in forming questions and I felt I was a valued partner. If I had concerns I could raise them and not only just raise them but the concerns would be valued as well. And often people would always thank me for my comments. (consumer/survivor researcher)
\end{abstract}

To capture the emerging voice of consumer/survivor researchers, we regularly reflected on our process and took notes of these discussions. Researchers wrote their own field notes of individual learnings, of struggles, and growth. At the end of the project, we held a team focus group where we formally interviewed each other about our experiences.

Reflecting on our experiences, we believe that working together with consumer/survivor researchers requires a shift of thinking regarding traditional roles and power relationships for professional researchers. The success of our team depended upon the professional researchers' willingness to share power with consumer/survivor researchers (Nelson, et al., 1998; Woodside et al., 1995).

Support and community. The value of supportive relationships and community refers to peer support and what Sarason (1988) called a "psychological sense of community." It also refers to reasonable accommodation within work settings (Ochocka, et al., 1994). Researchers supported each other in all research and non-research tasks and the Center for Research and Education provided a safe and accommodating workplace. Individual needs were accommodated by using flexible hours, by providing individualized support, by matching tasks with abilities and skills, and by using a team approach (Morrell-Bellai \& Boydell, 1994; Ochocka, et al., 1994).

The support was individualized, flexible, and ongoing. As professional researchers, we were sensitive to each person's situation and "checked-in" with everyone often enough to ensure that everyone was doing well. We built supportive relationships that created a strong foundation for all activities. Supportive relationships mean being respectful, sympathetic, and helpful in the way we talk, in the way we relate to each other, in the way we listen and respond.

I found a lot of compassion among my peers here at the Center when 1 struggled, when I felt ill again. The Center motivated me through your friendship. I was constantly aware of your concern for me, how I was doing and even the visits to the hospital were very appreciated. People here have a lot of compassion for people they work with and the consumers in the community. I really value the friendship with the people here...even if the project is over it's nice to know that the relationships will still be intact. I can't say the same for all my jobs I've ever had. (consumer/survivor researcher)

For the duration of the project, researchers were expected to support each other and to accommodate each other's needs by working as a team. Everyone participated in planning research activities and training, so every. one was able to do a variety of tasks. Also, researchers had an option to conduct interviews in pairs and debriefed together within the team. When one researcher was unable to conduct a focus group and to present at a conference, others did the job without any big fuss or problems. One researcher described how the research members were able to accommodate personal challenges:

My mental symptoms are persistent and became persistent last year. April was the first anniversary of my mom's death and I needed time away to recover. It was a challenge to not only get on top of my research work, but also to look after myself. But the Center, the team members here pulled together and were able to pull together my notes for me that I completed in a pretty decent package and [...] finished it right away. I was kept on track in other words, that challenge was met by the dedication driven by the Center and my recovery was okay. It was my shortest hospitalization ever and there was a lot of support from people at the Center, which was really helpful. (consumer/survivor researcher)

The research team, together with a few steering committee members who represented the three organizations in the study, also made the conference 
presentation held in Toronto. This educational experience bonded us as we shared pride in and ownership of the research study. As one person said, "our workshop in Toronto was wonderful, having everybody involved in this presentation." Another copresenter said,
A gentleman in the audience tried to challenge our group and our study.
We as a group defended the study and backed up each other.
Especially one of the consumer/sur- vivor researchers did a remarkable job. I had a strong feeling of solidar- ity among all of us. That day, it was evident that we all believed and pro- moted the paradigm shift. (profes- sional researcher)

In our study, accommodation was framed as a broader issue that related to all research team members, not only to consumer/survivor researchers.

Everyone needed some type of flexibility and accommodation in the project due to various life circumstances. This broad view helped us to see the issue of accommodation in more general terms and to share responsibilities of the project among all involved.

Perhaps the biggest challenge for the research team came during the third phase when we were trying to organize our case studies. Many of our potential research participants were experiencing difficultiessome were hospitalized even after they agreed to be a part of the study. Our timelines were being stretched further than we would have preferred. As a result, our graduate student researcher, who was to take on two of the six case studies, was feeling the pressure of time constraints due to her school demands. A couple of the consumer/survivor researchers were also experiencing more stress. It took a lot of flexibility and creative problem solving from different team members to arrange a way to get these two case studies completed. (professional researcher)
Technical support was also very important. Computers, dictation machines, and tape recorders were always available for researchers as well as technical support at the Center for Research and Education.

Learning as we go. "Learning as we go" is a value that emphasizes an educational component of participatory action research (Nelson, et al., 1998; Park, 1993). Training and educational opportunities were very important. Doing research was largely a new experience for most of the consumer/survivor researchers. Some were nervous and hesitant coming into the project.

Education and training occurred in several different ways. There were many structured or formal learning opportunities in the project. We started with the discussion of concepts like empowerment, stakeholder approach, and participatory action research. We held sessions about practical techniques in qualitative interviewing, participant observation, qualitative data analysis, ethics, and case studies. Also a few educational events were organized (conferences, community forum, feedback sessions, etc.) to give the researchers experience in making presentations.

\section{Expectations I had were to gain some skills in the area of research and that did occur. That occurred through the training, which I felt was top notch. In fact, I received better training here than I had in most of my university courses. (con- sumer/survivor researcher).}

Unstructured and informal learning happened during our research team meetings and in our conversations. The informal learning worked two ways, for consumer/survivor researchers and for professional researchers. For example, the consumer/survivor researchers verified questions being asked in interviews, they suggested better ways to ask them, and they provided context to interpret answers. Our interactions created mutual understanding, empathy for one another, and ongoing learning for all team members.

The training and teamwork were very important to me being able to participate successfully in the project. The training was broken down into manageable size pieces and applied as the project progressed. The teamwork was helpful especially at first when two of us would go out to do the focus groups. It gave me a lot more confidence to know a colleague was present and supportive and that I could work more independently in Phase III of the project. (consumer/survivor researcher).

Training was incremental and occurred as we moved along in the different research phases or steps in each phase. It was very helpful that training was not overwhelming (e.g., one event to learn everything up front) and was provided to the whole team, so people could learn from each other. We practiced skills by playing roles and solving dilemmas within the research team.

Social justice. Hiring and training consumer/survivor researchers was our principal way of fulfilling the value of social justice and access to valued resources (Nelson et al., 2001). We strongly believe that consumer/survivors have the right to research services they use and to access research resources. The involvement in research studies gives consumer/survivors employment opportunities, contacts with people and places, and important research and social skills.

The hiring of the consumer/survivor researchers was a joint effort between the community organizations and the Center for Research and Education. Although few candidates had much formal research experience in the past, researchers were hired on the basis of skills and experiences best lending themselves to conducting qualitative 
research. The three hired researchers were paid the standard hourly research assistant rate at the Center for Research and Education.

The type and degree of involvement of these researchers in their mental health organization varied. One researcher had received support from her organization at times in the past, but had relatively little contact with that organization in the last few years. At the end of the research project, this person received a part-time position within the organization. The researcher from the consumer/survivor self-help organization was an active member of that organization. During the first 2 years of the study, he was hired as a paid staff person of the organization and was promoted to Assistant Executive Director by the end of the project. The third researcher held a short-term contract staff position at the beginning of the study. By the end of the project, he had accepted a fulltime permanent position within the organization.

Researchers had opportunities to learn tasks and skills related to conducting research as well as other types of abilities. For example, they participated in staff meetings and educational/social events at the Center for Research and Education. All these opportunities had direct impact on their personal lives.

\section{LEARNINGS}

Employing consumer/survivor researchers in a research project made us aware of issues of power and control in all aspects of our work. We learned about the importance of shifting the way that professionals work with people who experience limited access to power and opportunities. There were two main factors that facilitated changes from traditional power relations. First, when professional researchers "let go" of some control over the research process, consumer/survivors have opportunities to "step up" and become more engaged. Second, it is important for professional researchers to practice good process, democratic involvement (voice and choice) and decision-making (consensus).

The main ideas that we learned regarding the reduction of power imbalances between professional researchers and consumer/survivor researchers are as follows: (a) the importance of building relationships among researchers that are meaningful, authentic, and supportive, and (b) the importance of adequate research training and support of consumer/survivor researchers.

\section{Importance of Building Relationships}

Building relationships within the research team took time and effort. As in our personal lives, research relationships needed to be nurtured by putting into practice values such as trust, honesty, and open communication. For us, this meant building trust, having shared beliefs, and "walking the talk."

I think for me it was an issue of building trust, of trusting this process. I think I came in with some degree of skepticism ... wondering if in fact it would be tokenism or not. And I don't believe it has been. (consumer/survivor researcher)

Our process of relationship building was slow and incremental, continuously nurtured and occasionally tested. Through open and honest communication, disagreements and frictions were overcome. Each partner was respected for his/her differences in background and perspectives. Successful relationships were those in which a common ground was found, and in which shared history and values were jointly created (Lord \& Church, 1998).

But I found people listened, they had very, very respectful communi- cation. People were very open too. There was an empathy ... when I struggled and I know others strug. gled, people were prepared to be there and take some time. (consumer/survivor researcher)

We learned about the value of flexibility in building relationships. Growth and change in the relationships meant questioning the assumptions we hold about others. We learned that relationships work best when all partners can share, support, and learn from each other.

\footnotetext{
For me personally, what was most important was the team spirit and positive energy [on the research team]; the willingness to do things in different ways. Because we present together, we write together, we discuss these things together, if somebody cannot do something, there are other people around and we all know exactly where we are in the process. (professional researcher)
}

Lincoln and Guba (1985) have suggested that authenticity should be an important criterion for community research. Authentic relationships mean being ourselves. We found that setting a tone of informality (e.g., being on a first name basis, celebrating each others' birthdays) enabled us to relate to each other both personally and professionally.

As the relationships among the research team members evolved and grew, we progressively shared more information at a personal level. As a team, we celebrated all project successes and shared and listened to other important facts from our private lives. The linking of private and public selves was critical in providing a safe and comfortable place for reflections and expressions. It was a combination of the personal and the professional that added "life" to our meetings.

The relationships amongst team members strengthened as the project progressed and there was 
cohesiveness and growing trust that was enhanced as everyone shared pieces of their personal lives. This created a comfortable environment that allowed me to be and participate even on those days when I was struggling with life. (consumer/survivor researcher)

Personal disclosure also helped to facilitate new friendships among researchers. Like other friendships, these new friendships were based on common interests and mutual respect. We found that by sharing common experiences we could, as Park (1993) said, speak in a "full voice." In the end, the researchers valued the relationships they had made with other researchers.

I'd have to say friendship, because I can talk to the members at the Center on issues and have discussion with them on things that don't relate to the project, like my personal life and other things that are going on-common interests. (consumer/survivor researcher)

\section{Importance of Training}

The combination of training, support, and continual reflection proved to be critical components to the success of our research team. Training, knowledge sharing, and skills building allowed for egalitarian interactions and relationships among the researchers. It also facilitated a culture of ongoing learning and improvement. We learned that training worked well when it was incorporated in all team meetings and when it was practiced in safe and supportive environment with stimulating discussions.

\section{Conclusions}

During the two and a half years of this research project we were constantly learning about ways of implementing the four guiding values in our research (Nelson, et al., 1998), which were instrumental for sharing power and con- trol. Empowerment, supportive relationships, learning as "we go," and social justice have been the guiding principles for everything we planned and did. Not everything went smoothly. For example, we experienced the challenges of working efficiently with a large research team and a small budget. We learned that being a supportive employer and colleague needs to be balanced with maintaining timelines for the research.

The following are some specific tips that we have learned by working with consumer/survivor researchers that might be useful in equalizing power differences between professional and nonprofessional researchers:

- Have a research team to implement the project. A team approach allows the sharing of responsibilities and rewards, as well as encouraging personal growth for each team member.

- Have regular researcher meetings. Training, support, updates, checkins, and clear communication foster a flow of information and feelings of personal control.

- Value the difference. Realize the variety of norms and perspectives.

Recognize that difference is essential to creativity and people's well-being. People do things differently and it is OK.

- Involve nonprofessional researchers in all aspects of the project. By working on different research tasks without hierarchical divisions, all researchers are exposed to the complexity of the research design and research process. It increases ownership of the project, builds skills for all involved and builds supportive networks of people who can work together on issues.

- Relate to each other as people, with strengths and weaknesses. Try to develop authentic relationships that merge the professional and private selves of all involved.

- Have realistic expectations. Being proactive in planning each research task, pairing more experienced researchers with those who have less experience, and providing honest feedback can avoid disappointments and feelings of failure.

- Celebrate small and big successes together. We have found this helps to create a positive climate that includes food, fun, laughter, and learning.

- Build a foundation of trust and collaboration. Active listening, ongoing invitations to collaborate, mutual understanding and meeting people where they are at can help to build this foundation.

- Recognize the importance of experiential knowledge. Consumer/survivors are "experts" and owners of their own experiences and can shape research questions and sug. gest ways of collecting information.

- Have an approach that is planned but flexible in its implementation. This helps to adapt the workplan, timelines, and budget lines to the current situation.

- Facilitate accommodation for the whole research team. Using a supportive team approach allows anyone to offer and request individualized support to help weather life's challenges.

- Use plain language. Try to present information in a simple and understandable way.

\section{SUMMARY}

Participatory action research is very well suited to work with consumer/survivors (Nelson, et al., 1998). Employing con- 
sumer/survivor researchers in community mental health research is a moral imperative in this type of research.

Consumer/survivors have a basic right to active participation in research about services and supports intended to be helpful to them. The challenge is to make this participation meaningful, authentic, and based on real partnership. We demonstrated that successful participatory action research depends on the willingness of professional researchers to share power with others (Nelson, et al., 1998). Working from clearly stated values and principles keeps the goal of power-sharing in clear focus, while using a participatory action research approach maintains a commitment to selfexamination, reflection and communication.

In summary, this participatory research study sheds light on the concepts and interrelationships of meaningful participation and employment of consumer/survivors in mental health research. Our study points to the importance of sharing power and knowledge in the research relationships. It is through these relationships that power imbalances can be reduced and that personal empowerment can be enhanced. As one of the researchers said:

I would recommend that other projects look at this project as an example of successful participatory action research. It was innovative and it was a good experience for me and it could be a good experience for other consumer/survivors. We were paid researchers. We were paid to do this work so we were truly integrated in this project ... And 1 think that the paradigm shift has been accomplished here, just by virtue of being hired as a researcher and being treated as a person. (consumer/survivor researcher)

\section{REFERENCES}

Canadian Alliance for Research on Schizophrenia (1994). A national strategy for research on schizophrenia. Journal of Psycbiatry and Neuroscience, 19 (5, Suppl.1), p. 3-5.

Carling, P. J. (1995). Return to community: Building support systems for people with psycbiatric disabilities. New York: The Guilford Press.

Church, K. (1992). Moving over: A commentary on power sharing. Toronto: Psychiatric Survivor Leadership Facilitation Program.

Church, K. (1996). Beyond "bad manners": The power relations of "consumer participation" in Ontario's community mental health system. Canadian Journal of Community Mental Healtb, 15(2), $27-44$.

Constantino, V., \& Nelson, G. (1995). Changing relationships between selfhelp groups and mental health professionals: Shifting ideology and power. Canadian Journal of Community Mental Health, 14(2), 55-69.

Everett, B., Martin, N., \& Moore, P. (1995). You are not alone. Canadian Journal of Community Mental Health, 14(2), 91-100.

Hyndman, B. (1995, April). Successful client participation in evaluation. Presentation summary prepared for the Conference of Prenatal Nutrition and Support Programs: Making evaluation work for you. Burlington, ON.

Lincoln, I., \& Guba, E. G. (1985). Naturalistic inquiry. Newbury Park, CA: Sage.

Lord, J. (1989). The potential of consumer participation: Sources of understanding. Canada's Mental Health, 37(2), 15-17.

Lord, J. (1991). Lives in transition: The process of personal empowerment. Kitchener, ON: Centre for Research and Education in Human Services.

Lord, J., (1994, August). Genuine partnerships: Challenges and opportunities. Keynote presentation to National Conference on Independent Living, Winnipeg, Manitoba.

Lord, J., \& Church, K. (1998). Beyond "partnership shock": Getting to "yes," living with "no." Canadian Journal of Rebabilitation, 12(2), 113-121.
Lord, J., \& Dufort, F. (1996). Introduction: Power and oppression in mental health. Canadian Journal of Community Mental Health, 15(2), 5-11.

Lord, J., \& Hutchison, P. (1997). Empowerment, disability and the community context. Rehabilitation Digest, $13-15$.

Lord, J., \& Hutchison, P. (1993). The process of empowerment: Implication for theory and practice. Canadian Journal of Community Mental Health, 12(1), 5-22.

Lord, J. Ochocka, J., Czarny, W., \& MacGillivary, H. (1998). Analysis of change within a mental health organization: A participatory process. Psychiatric Rebabilitation Journal, 21, 327-339.

MacGillivary, H., \& Nelson, G. (1998). Partnership values and processed in mental health: What it is and how to do it. Canadian Journal of Rebabilitation, 12(2), 71-82.

Mason, R., \& Boutilier, M. (1996). The challenge of genuine power sharing in participatory research: The gap between theory and practice. Canadian Journal of Mental Health, 15(2), 145-152.

Mateson, S. (1994). Rethinking the evaluator role: Partnerships between organizations and evaluators. Evaluation and Program Planning, 17(3), 299-304.

Morrell-Bellai, T., \& Boydell, K. (1994). The experience of mental health consumers as researchers. Canadian Journal of Community Mental Health, 13(1) 97-110.

Nelson, G., Lord, J., \& Ochocka, J., (2001) Shifting the paradigm in community mental bealth. Toronto: University of Toronto Press.

Nelson, G., Ochocka, J., Griffin, K., \& Lord, J. (1998). "Nothing about me, without me": Participatory action research with self-help/mutual aid organizations for psychiatric consumer/survivors. American Journal of Community Psychology, 26, 881-912.

Ochocka, J., Nelson, G., \& Lord, J. (1999). Organizational change towards the empowerment-community integration paradigm in community mental health. Canadian Journal of Community Mental Health, 18(2), 59-72.

Ochocka, J., Roth, D., \& Lord, J., (1994). Workplaces that work: Successful employment for people with disabilities. Journal on Developmental Disabilities, 3, 29-51. 
Pape, B. (1992). Consumer participation: from concept to reality. Toronto: Canadian Mental Health Association.

Park, P. (1993). What is participatory research? A theoretical and methodological perspective. In P. Park, M. Brydon-Miller, B. Hall, \& T. Jackson (Eds.), Voices of change: Participatory research in the United States and Canada (pp. 1-19). Westport, CT: Bergen \& Garvey.

Prilleltensky, I., \& Gonick, L. (1996). Politics change, oppression remains: On the psychology and politics of oppression. Journal of Political Psychology, 17, $127-148$.

Prilleltensky, I., Rossiter, A., \& Walsh-Bowers, R. (1996). Preventing harm and promoting ethical discourse in helping professions: Conceptual, research, analytical, and action frameworks. Ethics and Behavior, 6(4), 287-304.

Rappaport, J. (1987). Terms of empowerment/exemplars of prevention: Towards a theory for community psychology. American Journal of Community Psychology, 15, 121-144.

Reeve, P., Cornell, S., \& D'Costa, B. (1998). Experience of community researchers. News Report of the Centre for Research and Education in Human Services, $12: 1,4$.

Sarason, S. B. (1988). The psychological sense of community: Prospects for a community psychology. Cambridge, MA: Brookline.

Srebnick, D., Robinson, M., \& Tanzman, B. (1990, August). Participation of mental bealth consumers in research: Empowerment in Practice. Poster Session presented at the American Psychological Association Convention, Boston, MA.

Stewart, M., Banks, S., Crossman, D., \& Poel, J. (1994). Partnerships between health professionals and self-help groups: Meanings and mechanisms. Prevention in Human Services, 11, 199-240.

Trainor, J., Pomeroy, P., \& Pape, B. (Eds.). (1999). Building a framework for support: A community development approach to mental bealth policy. Toronto: Canadian Mental Health Association/National.
Trainor, J., Shepherd, M., Boydell, K., Leff, A., \& Crawford, E. (1996). Consumer/Survivor Development Initiative evaluation report. Toronto: Consumer Survivor Development Initiative.

Trainor, J., Shepherd, M., Boydell, K. M., Leff, A., \& Crawford, E. (1997). Beyond the service paradigm: The impact and implications of consumer/survivor initiatives. Psychiatric Rebabilitation Journal, 21, 132-140.

Vandergang, A., (1996). Consumer/survivor participation in the operation of community mental health agencies and programs in Metro Toronto: Input or impact? Canadian Journal of Community Mental Health, 15(2), $153-170$.

Vuong, D., \& St-Amand, N. (1993). What consumers think of the New Brunswick mental health system. Results of a research carried out with the psychiatrized. Our Voice/Notre Voix, 15, 1-12.

Wilson, S. (1996). Consumer empowerment in the mental health field. Canadian Journal of Community Mental Health, 15(2), 69-85.

Woodside, H., Cikalo, P., \& Pawlick, J. (1995). Collaborative research: Perspectives on consumer-professional partnerships. Canada's Mental Health, $43(1), 2-7$.

World Health Organization British Columbia Project. (1993). Consumer participation manual: A document to facilitate consumer participation in the mental bealth system. British Columbia: World Health Organization, British Columbia Project. 